\title{
Impact of Multi-ion Interactions on Oil Mobilization by Smart Waterflooding in Carbonate Reservoirs
}

\section{Awolayo AN* and Hemanta K Sharma}

Department of Chemical and Petroleum Engineering, University of Calgary, 2500 University Drive, N.W. Calgary, Alberta, Canada

\begin{abstract}
The injected brine composition has been observed to have intense effect on efficiency of waterflooding in carbonate reservoirs. This process is known as smart waterflooding and has proved to be an effective process in improving oil recovery. Different approaches have been tested in carbonate reservoirs due to the complexity of the process. Based on these approaches, different mechanisms have been proposed with some level of uncertainties. This has led to several arguments on the chemical mechanisms responsible for such feat achieved. One of the approaches is discussed in this paper, however with much interpretation considering all factors influencing the oil-brine-rock interactions. Therefore, this paper presents the influence of multi-ion interactions during smart water flood on carbonates. Sequential flooding of formation brine and smart brines and the effluent ion analysis were conducted to confirm the multi-ion interactions leading to improved recovery. In addition, zeta potential measurement was conducted to examine the alteration process and correlated with the core flood results. The results from zeta potential measurement showed that multi-ion interaction alters the rock surface charge, which led to more water-wetness. Significant improvement in oil displacement efficiency was observed beyond the secondary waterflood and effluent ionic analysis demonstrated that these multi-ionic interactions led to the observed alteration.
\end{abstract}

Keywords: Smart water; Zeta potential; Displacement; Alteration; Electrostatic forces; Ionic analysis

\section{Nomenclature}

BV: Bulk Volume; D: Diameter; IRF: Incremental Recovery Factor; IS: Ionic Strength; $\mathrm{K}_{\mathrm{L}}$ Liquid Permeability; $\mathrm{K}_{\mathrm{o}}$ Permeability To Oil; Kppm: Thousands Part Per Million; L: Length; OOIC: Original Oil In Core; PV: Pore Volume; RF: Recovery Factor; Swirr: Irreducible Water Saturation; TDS: Total Dissolved Solids; XRD: X-Ray Diffraction; Ø: Porosity; $\Theta$ : Contact Angle

\section{Introduction}

Waterflooding has been an effective and relatively inexpensive process of improving recovery beyond the primary natural drive. In carbonate reservoirs, which are always mixed/strongly oil-wet, waterflooding seems ineffective as water cut escalates leaving behind high residual oil saturation (ROS). In such case, rock wettability do not favour the optimal condition for oil displacement by the injection water.

Through the centuries in a reservoir, a thermodynamic equilibrium has existed between the brine, oil and the rock and there is no doubt that injecting different brine would considerably change this equilibrium. This is a major reason why the brine injected during convectional waterflooding is usually selected based its compatibility with existing formation brine. This change is linked with the interaction between the injected brine and the rock surface. However, decades of research has confirmed that the change is more positive towards improving oil recovery [1-4]. The brine-rock interaction has been observed to be prompted by the reactivity of the ions in the injected water, which is crucial in creating a surface charge alteration [5]

Furthermore, during smart waterflooding, it is predicted that as the injected water displaces the oil ahead, rock wettability is favourably altered along the way. Therefore, waterflooding is termed smart when the injected water's ionic composition and salinity are manipulated selective addition or removal of certain ions.
It is evident that a mechanistic study of smart water flood on lime stones (carbonates) is much more complicated as compared to its application on sandstones and chalk [2,6-13] probably as a result of divergent mechanisms working together with each individual influence. Sandstones possess less interaction between the polar components in the oil and its minerals and chalk having a higher surface area compared to lime stones [14-17].

Recently, there has been a rapid growth in the publications of smart waterflood laboratory experimental results on carbonates with very limited field trials and different mechanisms have been suggested to be accountable for the improved displacement efficiency [18]. Awkwardly, most of these suggested mechanisms are debatable, probably because many factors are involved which are associated with the reservoir fluids, rocks and the injection fluid. Although, wettability alteration is the widely accepted mechanism by researchers, other physical mechanisms suggested are fines migration, multi-ion exchange, surface charge alteration, double layer expansion, etc. The different mechanisms are associated with the different approaches that have been implemented in smart water flood on carbonates [19], which include;

I. Brine salinity reduction

a. Brine dilution.

b. Reduction of water hardness $-\mathrm{Ca}^{2+}, \mathrm{Mg}^{2+}$.

c. Reduction/Removal of non-active ions $-\mathrm{Na}^{+}, \mathrm{Cl}^{-}$.

Corresponding author: Awolayo AN, Department of Chemical and Petroleum Engineering, University of Calgary, 2500 University Drive, N.W. Calgary, Alberta, Canada. T2N 1N4, Tel: 403-397-7639; E-mail: adedapo.awolayo@ucalgary.ca

Receive April 28, 2016; Accepted May 20, 2016; Published May 28, 2016

Citation: Awolayo AN, Sharma HK (2016) Impact of Multi-ion Interactions on Oil Mobilization by Smart Waterflooding in Carbonate Reservoirs. J Pet Environ Biotechnol 7: 278. doi:10.4172/2157-7463.1000278

Copyright: (c) 2016 Awolayo AN, et al. This is an open-access article distributed under the terms of the Creative Commons Attribution License, which permits unrestricted use, distribution, and reproduction in any medium, provided the original author and source are credited. 


\section{Ionic modification}

a. Surface interaction ion concentration increment $-\mathrm{SO}_{4}^{2-}, \mathrm{PO}_{4}^{3-}$, $\mathrm{BO}_{4}^{3-}$.

b. Potential determining ions, $\mathrm{PDI}-\left(\mathrm{SO}_{4}^{2-}, \mathrm{Mg}^{2+}, \mathrm{Ca}^{2+}\right)$ concentrations.

In previous works by Fathi et al. [20], the potential of smart waterflood has been explored through the second approach to enhance oil mobilization. Although this technique has a number of merits, its potential was thoroughly investigated in carbonates to achieve optimal concentrations and particularly in the high-temperature $\left(110^{\circ} \mathrm{C}\right)$, highpressure $(20 \mathrm{MPa})$ and high-salinity $(200-250 \mathrm{kppm})$ environment. This work is therefore focused on the first approach to better understand the underlying chemical mechanisms through experimental studies and then breed a database on the impact multi-ion interaction in a smart waterflood conducted under reservoirs conditions.

\section{Experimental Section}

\section{Materials}

Core plugs: Carbonate cores with consistent properties were selected based on routine core analysis, which was first conducted to measure the dimensions, air permeability, porosity, and pore volume of the core plugs. Table 1 shows their detailed properties. Core plates cut from plugs into rectangular shape dimension $(1.27 \mathrm{~cm} \times 1.905 \mathrm{~cm}$ $\times 0.762 \mathrm{~cm}$ ) were used for the contact angle measurements. Part of the rock was crushed to conduct X-ray diffraction (XRD) analysis; the result showed in Figure 1 reveals that the main rock composition is calcite with little trace of minerals like dolomite and quartz.

Fluid properties: All synthetic brines were prepared according to the geochemical formulations listed in Table 2 by dissolving specified amounts of reagent-grade salts in deionized water. The brines consisted of formation water named as "FW" which is classified as the base brine, used in establishing irreducible water saturation and secondary flooding; and various smart brines, which are injected after base brine and possibly to trigger incremental recovery. Likewise, smart brines were prepared based on seawater compositions by brine dilution and

\begin{tabular}{|c|c|c|c|c|c|c|c|}
\hline $\begin{array}{c}\text { Sample } \\
\text { ID }\end{array}$ & L [cm] & $D[\mathrm{~cm}]$ & $\varnothing[\%]$ & $\mathrm{K}_{\mathrm{L}}[\mathrm{mD}]$ & $\mathrm{PV}\left[\mathrm{cm}^{3}\right]$ & OOIC $\left[\mathrm{cm}^{3}\right]$ & Swirr \% \\
\hline$P \# 1$ & 6.37 & 3.84 & 30.78 & 9.91 & 22.32 & 17.80 & 21.10 \\
\hline$P \# 6$ & 6.22 & 3.81 & 29.16 & 6.11 & 20.55 & 17.00 & 17.27 \\
\hline$P \# 8$ & 7.11 & 3.86 & 25.34 & 18.35 & 20.48 & 15.00 & 26.8 \\
\hline
\end{tabular}

Table 1: Core plugs petro-physical properties.

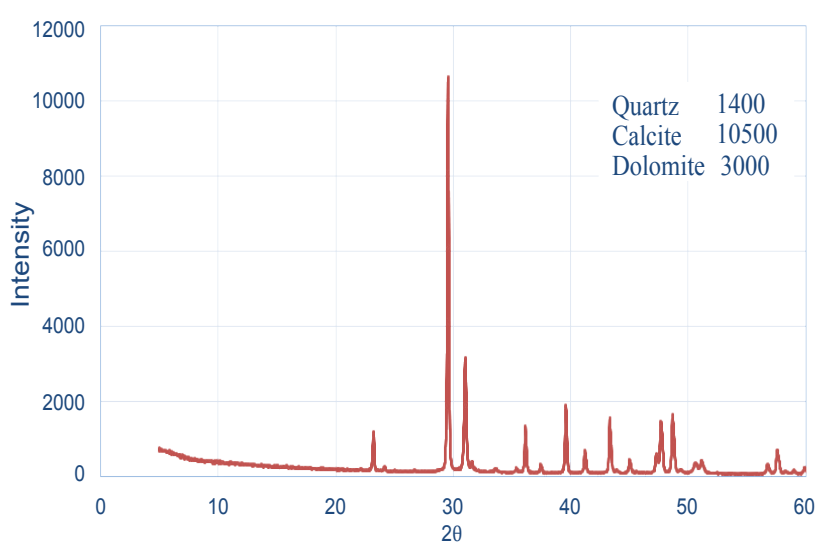

Figure 1: XRD analysis.

\begin{tabular}{|c|c|c|c|c|c|c|c|c|c|}
\hline $\begin{array}{c}\text { Brines/lons } \\
{[\mathrm{kppm}]}\end{array}$ & $\mathrm{Na}^{+}$ & $\mathrm{Ca}^{2+}$ & $\mathrm{Mg}^{2+}$ & $\mathrm{K}^{+}$ & $\mathrm{SO}_{4}^{2-}$ & $\mathrm{HCO}_{3}^{-}$ & $\mathrm{Cl}^{-}$ & TDS & IS \\
\hline $\mathrm{FW}$ & 76.68 & 19.12 & 3.35 & 0.08 & 0.11 & 0.06 & 161.81 & 261.21 & 5.19 \\
\hline $\mathrm{SW}$ & 13.64 & 0.39 & 1.73 & 0.01 & 2.85 & 0.01 & 24.65 & 43.28 & 0.87 \\
\hline $\mathrm{DSW}$ & 1.00 & 0.06 & 0.18 & 0.00 & 0.32 & 0.01 & 1.95 & 3.52 & 0.07 \\
\hline SWONaCl & 1.51 & 0.54 & 1.73 & 0.01 & 3.08 & 0.01 & 6.04 & 12.91 & 0.35 \\
\hline DSW0NaCl & 0.22 & 0.06 & 0.18 & 0.00 & 0.34 & 0.01 & 0.71 & 1.52 & 0.04 \\
\hline \multicolumn{8}{c|}{ Table 2: Brine geochemical compositions. }
\end{tabular}

removal of $\mathrm{NaCl}$; their nomenclature imitates the relative alteration in their composition. In this work, seawater is termed as "SW", Ten times diluted seawater as "DSW", seawater with selective removal of $\mathrm{NaCl}$ as "SWONaCl" and Ten times diluted seawater with selective removal of $\mathrm{NaCl}$ as "DSW0NaCl.

Core preparation: The core plugs were first subjected to solvent cleaning using Dean-Stark extraction and dried at $100^{\circ} \mathrm{C}$ for about 24 hours prior to petro-physical measurements. Then the plugs were saturated with FW under vacuum for around 72 hours in order to establish equilibrium. The pore volume (PV) was calculated from weight difference and compared to the one estimated from the helium porosity measurement (comparison gave an error of $<2 \%$ ). Field dead oil (with about $5 \mathrm{PV}$ ) was then injected in each direction into the cores to establish irreducible water saturation, and the cores were aged using steel aging cell under experimental temperature $\left(110^{\circ} \mathrm{C}\right)$ and around 13.8 MPa for 6weeks. Before starting the flooding test, more than $1 \mathrm{PV}$ dead oil was injected into the core to displace the oil used during aging and the effective permeability to oil at irreducible water saturation was recorded.

Core flooding and chemical analysis: The experimental setup is similar to the one discussed in our previous work [19]. Each waterflood test commenced with the base brine at a constant injection rate of $0.25 \mathrm{cc} / \mathrm{min}$. Once the oil production ceased, it was followed by sequential injection of smart brines. All experiments were conducted at $100^{\circ} \mathrm{C}, 20 \mathrm{MPa}$ pore pressure, and $10.3 \mathrm{MPa}$ net confining pressure with horizontal orientation. The ionic concentrations of $\mathrm{Ca}^{2+}, \mathrm{Mg}^{2+}, \mathrm{SO}_{4}^{2-}$, $\mathrm{Cl}^{-}$and $\mathrm{Na}^{+}$were analysed by an ion-exchange chromatograph pre and post coreflooding tests, in order to better interpret the observed results.

Contact angle monitoring: Advancing contact angles were measured on core plates to verify the wettability alteration process by smart water. First, the polished core plates were placed under vacuum for at least two hours and aged in the base brine for another 24 hours. Then the plates were aged in the field dead oil at reservoir temperature of $110^{\circ} \mathrm{C}$ for at least 6 weeks to restore the wettability. Because of the limitations to water boiling at $100^{\circ} \mathrm{C}$, the test was carried out at $95^{\circ} \mathrm{C}$, so the brines were preheated to $95^{\circ} \mathrm{C}$ before commencement. Then, the plates were exposed to different brines. The monitoring were performed immediately after aging as a reference, and then at different periods of time that the plates had been exposed to the different brines as described by Awolayo [20].

Zeta potential experiment: The zeta potential of brine/rock interface of the aqueous rock suspension was measured by using a Zeta Electroacoustic Spectrometer. A representative solution was prepared using the base brine and pulverized core sample according to procedures described by Awolayo [19]. The initial charge at the interface was then measured before being re-measured as different smart waters were mixed with the representative solution. Solution $\mathrm{pH}$ was also reported with the zeta potential measurement. In order to better understand the relationship between surface charge and oil recovery, this study is significant as several studies reported little could be done to alter oil/ brine interface charge from strongly negative (Table 3 ). 


\section{Results and Discussion}

This section summarizes the results complemented by critical cognitive discussions on the experimental studies where FW was set as a baseline to compare the performance of other smart brines.

\section{Surface charge of carbonates}

The charges at oil/brine and brine/rock interfaces primarily control the stability of the water film between the oil and rock, hence the rock wetting state. If the two interfaces possess similar surface charges, then a strong repulsive force is created and if opposing charges, a strong attractive force is generated. A strong electrostatic repulsion between the interfaces will create a stable and thick water film which would results in water-wet rock [19]. The rock wettability could change towards oilwet if weak electrostatic repulsion exists between the interfaces leading to unstable and thin water film. Therefore, rock wettability depends on the sign and magnitude of the electrical charges at the two interfaces due to the electrostatic attractive or repulsive forces generated between them. The results showed positive surface charges at the rock/brine interface at all range of salinity and they are discussed below;

Surface charge with salinity dilution: The baseline condition $\left(\mathrm{SO}_{4}^{2-}: \mathrm{NaCl}=1: 2129.4\right)$, gave a positive zeta potential value of 4.49 $\mathrm{mV}$ at a solution $\mathrm{pH}$ of $7.33 ; \mathrm{SW}\left(\mathrm{SO}_{4}{ }^{2-}: \mathrm{NaCl}=1: 11.6\right)$, gave a positive value of $2.2 \mathrm{mV}$ at a solution $\mathrm{pH}$ of 8.08 . While introduction of DSW $\left(\mathrm{SO}_{4}{ }^{2-}: \mathrm{NaCl}=1: 11.6\right)$ gave a zeta potential value of $2.26 \mathrm{mV}$ at a solution $\mathrm{pH}$ of 7.79 . Figure 2 presents effect of brine dilution on zeta potential as a function of $\mathrm{pH}$.

The result indicates that brine salinity/ionic strength reduction due to brine dilution results in increasing the rock surface charges which is influenced by decreased in solution $\mathrm{pH}$. This result trend means so far the ratio between the active $\left(\mathrm{SO}_{4}^{2-}\right)$ and the non-active ions concentration remain the same, no further alteration of charges could be obtained. This is due to the fact that the active ions responsible to decrease the brine/rock surface charge were in low concentrations.

Surface charge with non-active ions depletion: Also, analysis of the case where brine salinity/ionic strength was reduced by nonactive ions depletion, the baseline $\left(\mathrm{SO}_{4}{ }^{2-}: \mathrm{NaCl}=1: 2129.4\right)$ gave a zeta potential value of $4.49 \mathrm{mV}$ at a solution $\mathrm{pH}$ of 7.33 . Then with
$\mathrm{SW}\left(\mathrm{SO}_{4}{ }^{2-}: \mathrm{NaCl}=1: 11.6\right)$, gave a zeta potential value of $2.2 \mathrm{mV}$ at a solution $\mathrm{pH}$ of 8.08 . Introduction of $\mathrm{SW} 0 \mathrm{NaCl}\left(\mathrm{SO}_{4}{ }^{2-}: \mathrm{NaCl}=1: 2.5\right)$ gave a zeta potential value of $1.54 \mathrm{mV}$ at a solution $\mathrm{pH}$ of 7.86 as shown in Figure 3a. This same trend was also observed with DSW $\left(\mathrm{SO}_{4}{ }^{2-}: \mathrm{NaCl}\right.$ $=1: 11.6$ ) which gave a zeta potential value of $2.26 \mathrm{mV}$ at a solution $\mathrm{pH}$ of 7.79 while $\mathrm{DSW} 0 \mathrm{NaCl}\left(\mathrm{SO}_{4}^{2-}: \mathrm{NaCl}=1: 2.7\right)$ gave a zeta potential measurement of $2.1 \mathrm{mV}$ at a solution $\mathrm{pH}$ of 7.92 as shown in Figure $3 \mathrm{~b}$.

The result shows that brine/rock interface charge is significantly altered with the removal of non-active ions from the smart brine. Also the removal reduces the brine salinity and the ratio between the active and non-active ions, which prompted the electrical double layer (EDL) expansion as there is increased repulsion between the two interfaces. Likewise as sulphate is more electronegative compared to chloride, depleting smart brines in chloride as a non-active ion would tend to create more reactivity for sulphate ion towards the rock surface. Just as

\begin{tabular}{|c|c|c|c|}
\hline Fluids & FW & SW & DSW \\
\hline Density $\left[\mathrm{g} / \mathrm{cm}^{3}\right]$ @ 20 $20^{\circ} \mathrm{C}$ & 1.1728 & 1.0306 & 1.001 \\
\hline Viscosity [cP] @ 70 $\mathrm{C}$ & 0.815 & 0.463 & 0.435 \\
\hline Fluids & SW0NaCl & DSW0NaCl & Oil \\
\hline Density [g/cm $\left.{ }^{3}\right] @ 20^{\circ} \mathrm{C}$ & 1.0089 & 0.9992 & 0.8376 \\
\hline Viscosity [cP] @ 70 $\mathrm{C}$ & 0.471 & 0.429 & 1.927 \\
\hline
\end{tabular}

Table 3: Brine and dead oil properties.

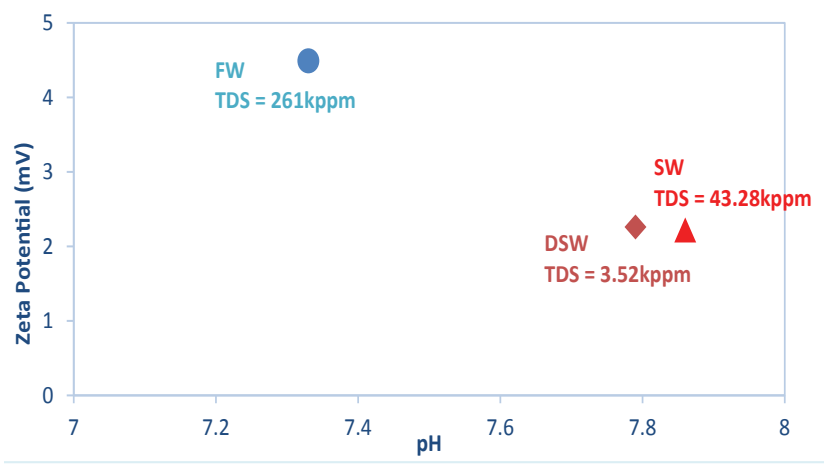

Figure 2: Surface charge variation with $\mathrm{pH}$ and brine dilution.

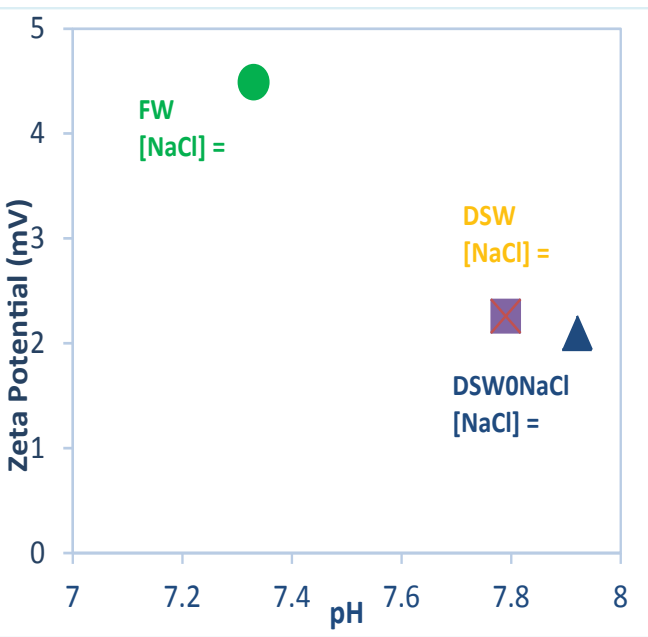

b.

Figure 3: Surface charge variation with $\mathrm{pH}$ and non-active ions depletion. 
discussed earlier, it can be noted that reducing brine salinity through the removal of non-active ions could favourably increase recovery.

\section{Core flood and ionic analysis}

Corefloods were conducted to study the impact of the ionic interaction in smart brines on oil recovery. The displacement efficiency and differential pressure were recorded. The effluents were collected for ionic analysis and the results were normalized against the injected composition and correlated with the observed oil displacement efficiency to further reaffirm the postulated mechanisms. For the ionic analysis, much emphasis is placed on the tertiary injections.

Core flood 1: After aging $\mathrm{P} \# 1$, it was flooded sequentially with FW, SW and SWONaCl. A longer period of flushing was to ensure any remaining mobile oil is displaced before commencing the injection of subsequent brines. This crucial step was to examine the effect of smart water on residual oil saturation and ultimately on displacement efficiency. A displacement plateau of $77.8 \%$ OOIC was established by about $8 \mathrm{PV}$ FW injection and no mobile oil was further displaced. Before breakthrough, 67\% OOIC was recovered after about 5.7PV injection. This established that residual oil is what was left in the core, which cannot just be recovered by FW. The initial oil saturation was observed to decrease to $17.5 \%$ by about $11 \mathrm{PV}$ injected.

Then, the injection fluid was switched to SW and an additional $2.4 \%$ OOIC was recorded. Thereafter, $\mathrm{SW} 0 \mathrm{NaCl}$ was injected and oil displacement efficiency increased to $87 \%$ OOIC. The displacement by $\mathrm{SW}$ and $\mathrm{SW} 0 \mathrm{NaCl}$ gave about 1.95 and $5.4 \%$ reduction in ROS respectively as shown in Figure 4. As smart water of lower salinity was introduced, the differential pressure decreased and later stabilized. This same observation was reported by Yousef [15]. The observed pressure drop reduction, in line with their argument, is due to the reduced capillary forces encountered as water saturation increases to displace the residual oil left in the sample. Similarly according to Gupta et al. [21], the pressure reduction could also be as a result of additional oil recovery owing to the injection switch to brines of lower viscosity which increases the mobility of the brine. The pressure stability was then as a result of one-phase flow of brine after displacing all mobile oils from the core.

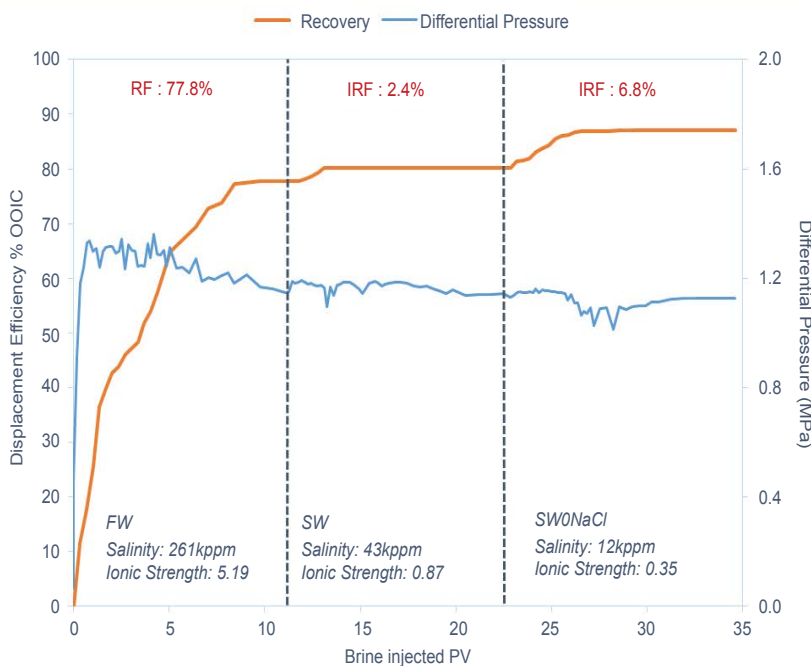

Figure 4: Displacement efficiency, injection rate and pressure drop as function of brine injected PV for P\#1.
Physical observation of the effluent shows less turbidity. During the SW injection (Figure 5), the $\left[\mathrm{Ca}^{2+}\right]$ increased immediately and started declining due to the dilution between FW and SW, but didn't not return to 1 as all normalized concentrations are expected to drop to 1 if no reaction, ionic exchange or dissociation was occurring. Also the $\left[\mathrm{Mg}^{2+}\right]$ reduced in the effluent and gradually increase to the injection level, perhaps because $\mathrm{Mg}^{2+}$ displaced $\mathrm{Ca}^{2+}$ from the rock surface at high temperature $\left(110^{\circ} \mathrm{C}\right)$. This could mean that $\left[\mathrm{Ca}^{2+}\right]$ not returning back to normalized concentration of 1 was as a result of ionic exchange process and calcite dissolution as $\left[\mathrm{Ca}^{2+}\right]$ didn't return to the injection level. Then $\left[\mathrm{SO}_{4}^{2-}\right]$ reduced denoting easy penetration of $\mathrm{SO}_{4}^{2-}$ through the diffuse layer into the stern layer as the non-active ions $\left(\mathrm{Na}^{+}\right.$and $\mathrm{Cl}$ ) concentrations in the effluent increased.

The non-active ions were high initially and steeply declined until almost constant at an equilibrium value which is due to the dilution of FW with SW (containing less non-active ions) as observed in Figure 6. At the stage where the non-active ion concentrations in the effluent were high, $\mathrm{SO}_{4}^{2-}$ adsorbed strongly to the rock surface with increased co-adsorption of $\mathrm{Mg}^{2+}$, thereby releasing the oil. This change in ion potential and adsorbed components alters the rock surface wettability and stimulates further imbibition of water, leading to improved oil mobilization. This trend align with the proposed mechanism by Zhang et al. as they identified $\mathrm{Mg}^{2+}$ and $\mathrm{SO}_{4}{ }^{2-}$ as responsible for the alteration at high temperature [12]

Prior to the injection of SWONaCl, the concentration of $\mathrm{SO}_{4}^{2-}$ in the effluent increased due to the fact no further wettability alteration occurred and this was when the recovery plateau had been established. During the SW0NaCl injection (most of its non-active ions depleted), similar to what has been explained above, but intensely higher was the non-active ions concentration in the effluent. The dilution of SW with SWONaCl generated the increased concentration which monotonically decreased but not to the injection level as the injected PV of SWONaCl increased.

Since non-active ions have been displaced from the diffuse layer, $\mathrm{SO}_{4}^{2-}$ gained better access to the stern layer and onto the rock surface. This caused its reduction in the effluent while it remained below the injection level. Reduced $\left[\mathrm{Ca}^{2+}\right]$ in the effluent at the onset of SWONaCl injection signifies that more $\mathrm{Ca}^{2+}$ attached to the rock surface due to simultaneous increased $\mathrm{SO}_{4}^{2-}$ adsorption; while $\left[\mathrm{Mg}^{2+}\right]$ went to settle at 1.15 times the SW slug which could create a small surface dolomite dissolution as XRD analysis proved presence of dolomite in the core. In this case, reduction of the salinity/ionic strength of injected fluid were achieved by reducing the concentrations of the non-active ions $\left(\mathrm{Na}^{+}\right.$ and $\mathrm{Cl}^{-}$). The increased oil recovery by $\mathrm{SW}$ and $\mathrm{SW} 0 \mathrm{NaCl}$ are related to their abilities to reduce the surface charge and dissolve minerals at the core surface.

Therefore, it can be recalled that FW contained very high concentration of non-active ions, $\mathrm{Na}^{+}$and $\mathrm{Cl}^{-}$. These ions are not considered active in wettability alteration process but majorly dominate the diffuse layer, which can create a barrier for the active ions to easily access the rock surface. As SW was introduced, with reduced concentration of $\mathrm{NaCl}$, the active ions get more access to the surface. Then at the reservoir temperature, sulphate adsorption created more electrostatic repulsion and facilitated the substitution of $\mathrm{Ca}^{2+}$ by $\mathrm{Mg}^{2+}$ at the rock surface, thereby leading to a substantial incremental recovery [12]. The recovery plateau was established once the diffuse layer was re-occupied by the non-active ions and barred the entrance of the active ions.

Then there is composition change in the diffuse layer by the introduction of smart water depleted in $\mathrm{NaCl}$, which increases the 


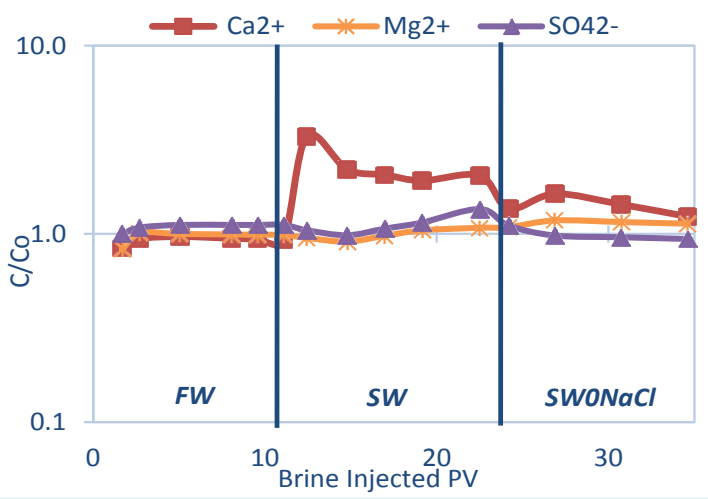

a. Active

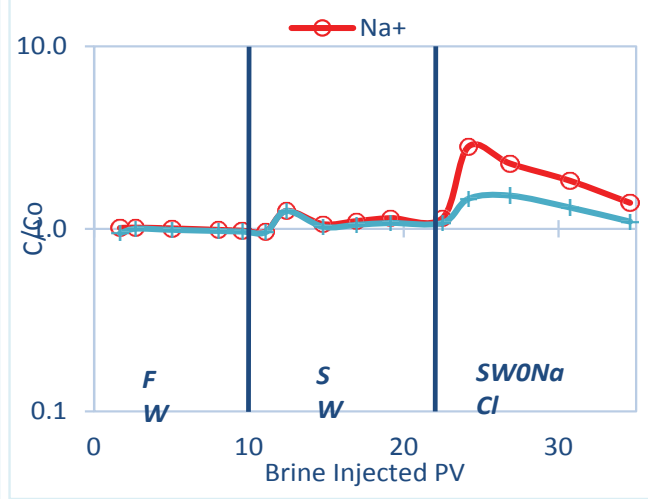

b. Non-active

Figure 5: Breakthrough curves for core flood 1.

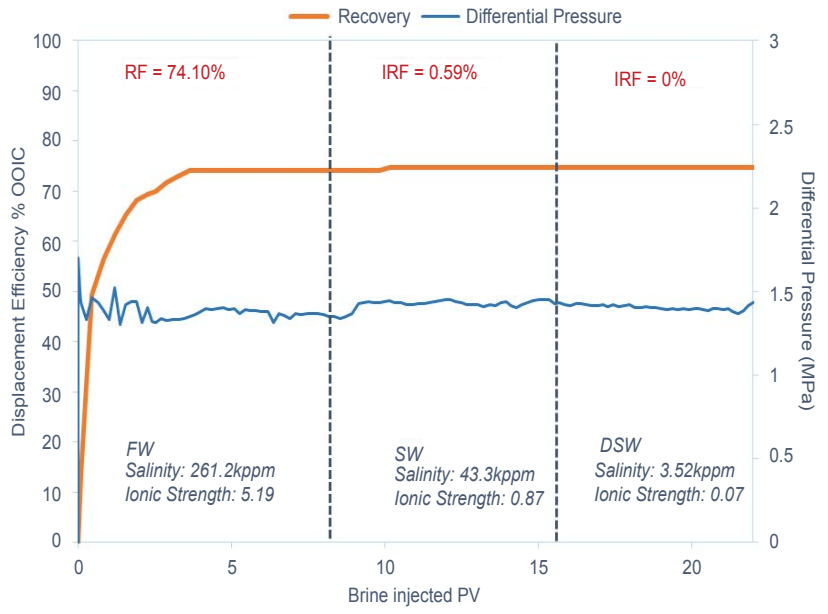

Figure 6: Displacement efficiency and pressure drop as a function of brine injected PV for P\#6.

activity of the active ions. This led to the active ions possessing better access to the rock surface. Increased adsorption of sulphate resulted, which lowered the positive charge on the rock surface and changed the established thermodynamic equilibrium. Then the availability of excess $\mathrm{Ca}^{2+}$ and $\mathrm{Mg}^{2+}$ at the rock surface, allowed formation of a complex compound with the organic component in crude oil and led to the desorption of more organic materials. The response from this double layer effect is wettability alteration towards more water-wetness and increased oil recovery as observed by Fathi et al. on chalk core materials [22]. Although, chalk $\left(2 \mathrm{~m}^{2} / \mathrm{g}\right)$ has been reported to possess significant larger surface area compared with limestone $\left(0.3 \mathrm{~m}^{2} / \mathrm{g}\right)$ but both have similar chemical composition, $\mathrm{CaCO}_{3}[5,14]$.

Core flood 2: Same procedures as mentioned above was followed only that P\#6 was flooded sequentially with FW, SW and DSW. The baseline injection reached a recovery plateau of $74.1 \%$ OOIC in about $2.89 \mathrm{PV}$ before oil production ceased. The initial oil saturation was $82.7 \%$ and decreased to $21 \%$ by waterflooding. Then the injection fluid was changed to SW and an incremental recovery of $0.59 \%$ OOIC was recorded. The reduced incremental recovery observed here as compared to first case was probably due to the differences in rock characteristics and heterogeneities. Then SW was replaced by DSW and in about 5.62PV, no substantial oil recovery was observed (Figure 6).
It can be inferred that reducing only the salinity/ionic strength without altering the concentrations of the active/non-active ions (SW - $43 \mathrm{kppm}$ to DSW - $3.52 \mathrm{kppm}$ ), could not mobilize additional oil. The pressure drop profile showed a decrease in pressure and later stabilization as the brine salinity reduces just as discussed in the first case.

The relative ion profile is shown in Figure 7a shows that during SW injection, $\left[\mathrm{Ca}^{2+}\right]$ increased in the effluent and later decreased but couldn't return back to the injection level, probably because of rock dissolution which produces more $\mathrm{Ca}^{2+}$ into the effluent. [ $\mathrm{SO}_{4}^{2-}$ reduced in the effluent coinciding with high concentration of non-active ions in the effluent while $\left[\mathrm{Mg}^{2+}\right]$ was constant. $\mathrm{SO}_{4}^{2-}$ could penetrate easily, then adsorbed to the rock surface and release the oil but little displacement was observed due to inability of the divalent ions to co-adsorb. This agrees with Zhang and Strand. where they concluded that $\mathrm{SO}_{4}{ }^{2-}$ must act together with $\mathrm{Ca}^{2+}$ and $\mathrm{Mg}^{2+}$ in order to obtain substantial recovery $[12,23]$. While the rock dissolution might have occurred in the pores already swept by the FW and denied the divalent ions the ability to co-adsorb.

Nil production observed during the DSW injection is as a result of the low concentration of active ions found in the injected brine. Then, the non-active ions concentration in the effluent settled around the normalized concentration value of 1.2 (Figure $7 \mathrm{~b}$ ). This indicates that sufficient amount of non-active ions were observed in the diffuse layer; thereby the active ions $\left(\mathrm{Ca}^{2+}, \mathrm{Mg}^{2+}\right.$ and $\left.\mathrm{SO}_{4}^{2-}\right)$ were prohibited access to the rock surface. This led to increase concentration of the active ions in the effluent.

For the period of DSW injection, the non-active ion concentrations increased and then declined until they reached an equilibrium value at the injection level. Correspondingly, $\left[\mathrm{SO}_{4}^{2-}\right]$ was at 1.2 times the DSW slug and didn't return to the injection level, which indicates no interaction with the rock surface. Then $\left[\mathrm{Ca}^{2+}\right]$ and $\left[\mathrm{Mg}^{2+}\right]$ settled above and around the normalized concentration respectively. This case differs from the previous case due to the fact that here salinity was reduced by diluting SW. As for the baseline injection, the displacement efficiency was similar to that observed in the previous case. Then the efficiency of SW flooding in this case is comparatively low as likened to previous case probably due to independent adsorption of $\mathrm{SO}_{4}^{2-}$ observed during the effluent ionic analysis. Sulphate multi-ion exchange process was thought to be responsible in this case, which might have caused marginal recovery due to inability of divalent ions to help sulphate compete with the carboxylic group [17]. In a study by Gupta and Mohanty [24], they also concluded that $\mathrm{SO}_{4}{ }^{2-}$ can alter rock wettability to a larger degree in the presence of $\mathrm{Mg}^{2+}$ and $\mathrm{Ca}^{2+}$ than in their absence. 


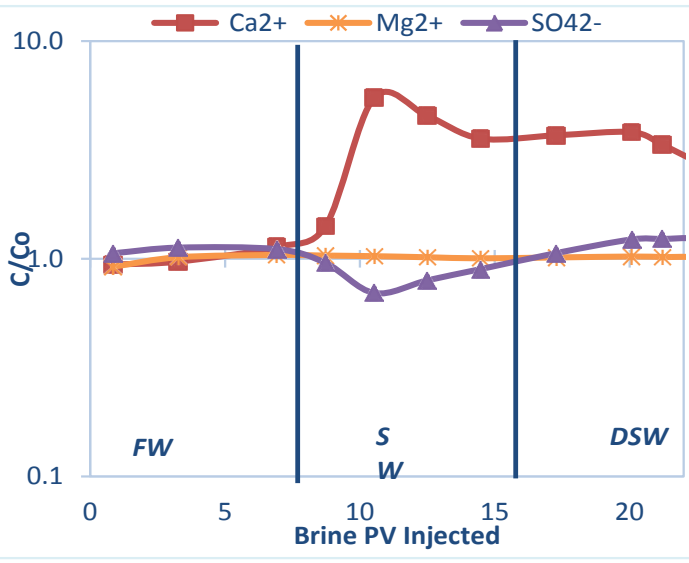

a. Active

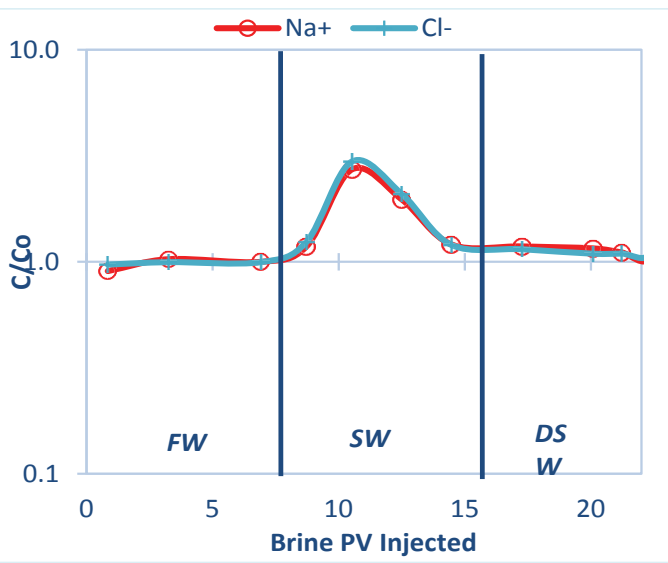

b. Non-active

Figure 7: Breakthrough curves for Core flood 2.

Core flood 3: This core flood was carried out to further confirm the observation made during coreflood 2 and here, the core, $\mathrm{P} \# 8$, was flooded sequentially with $\mathrm{FW}, \mathrm{SW} 0 \mathrm{NaCl}$ and $\mathrm{DSW} 0 \mathrm{NaCl}$. Injection of regular FW recovered $64.63 \%$ OOIC and oil production ceased in about 6.6PV. No further production was observed for continuous injection of FW (about 5PV more), which was to ensure all the mobile oil was thoroughly flushed out. The oil saturation was reduced from $74.2 \%$ to $25.91 \%$ which slightly differs from the previous cases.

Then the injection fluid was changed to $\mathrm{SW} 0 \mathrm{NaCl}$ (lower ionic strength and salinity) and an incremental recovery of $1.33 \%$ OOIC was documented, reaching its recovery plateau after $2 \mathrm{PV}$ injection. Then the injection fluid was replaced with DSW0NaCl and after $5 \mathrm{PV}$ injection, no additional oil recovery was observed as in Figure 8. Before the experiment, fractures were observed through the core sample and this limited the displacement efficiency as observed in other coreflooding results. This resulted in the little displacement efficiency observed during SWONaCl flooding as compared to the Coreflood 1. This is due to the fractures diverting most of the flow to the swept zone thereby resulting in mineral dissolution of the calcite surface.

Similar observation in the breakthrough curves as shown above was made compared to coreflood 2, except that the effects are more pronounced. This case placed more emphasis on the fact reducing brine salinity by just brine dilution couldn't result in improved oil recovery (Figure 9). The inability to recover additional oil could be attributed to the following reasons:

a) Presence of sufficient amount of non-active ions in the diffuse layer which could deny the relatively small concentration of active ions access to the rock surface [22].

b) A film was formed by the residual oil after $\mathrm{SW} / \mathrm{SW} 0 \mathrm{NaCl}$ injection that prohibited DSW/DSW0NaCl from interacting with the rock surface [25].

This result once again proves that diluting injection water could not recovery additional oil, which agrees to conclusions from Gupta, Fathi, RezaeiDoust and Austad et al. [21,22,26,27]. But seems to conflict with those from Alotaibi et al. Yousef et al., Zahid et al., Yi and Sarma and Chandrasekhar and Mohanty [15-17,28,29], where they maintained that diluting injection water have a significant impact on oil recovery accompanied with high pressure differential. Moreover, the dissimilarity could be as a result of different rock typing. Then Austad

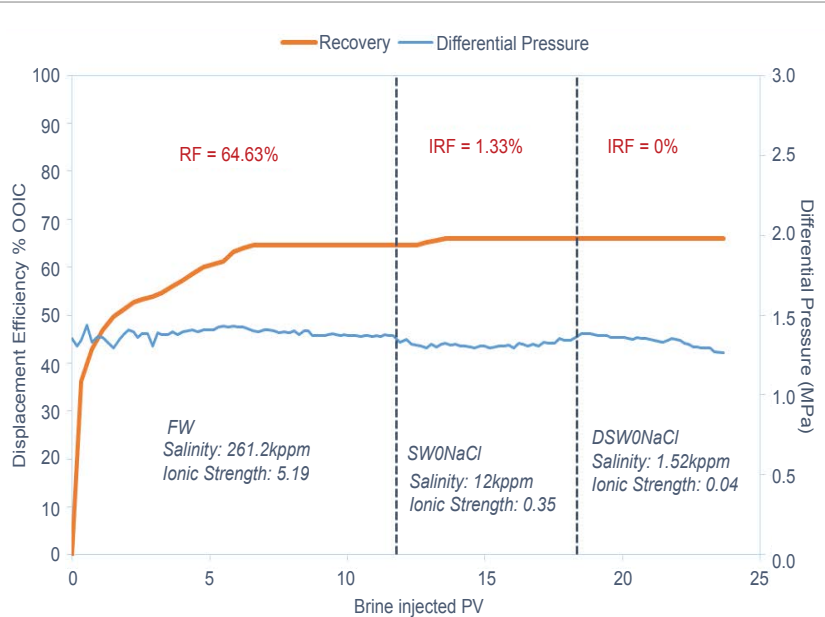

Figure 8: Displacement efficiency and pressure drop as a function of brine injected PV for P\#8.

described that brine salinity reduction by diluting injected water could only give incremental recovery in case there is anhydrite present in the carbonate core. However in this case XRD analysis showed the absence of anhydrite from all core samples used, which would be the reason for not observing incremental recovery during DSW injection. Gupta reported that the effectiveness of smart water with lower salinity was mainly due to the reduction of the divalent cation concentration rather than dilution of the injected water [21].

\section{Wettability monitoring}

Principally, this study was to investigate the wettability alteration by smart water as the principal mechanism responsible for improved oil recovery and further support evidence presented by the surface charge alteration. The influence of various smart brines on wettability was tested by evaluating the contact angle of oil droplet on the core plates and plotted against exposure time as shown in Figure 10.

Exposure to high saline brine (FW) could only maintain the rock wettability in the range of preferentially oil-wetting state. Then low saline brine (SW) drastically decreased the contact angle from $170.5^{\circ}$ to $148.2^{\circ}$ during the first $40 \mathrm{hrs}$ and with time further decreased to an equilibrium value of $119.8^{\circ}$ which seems to adjust the rock's wettability 

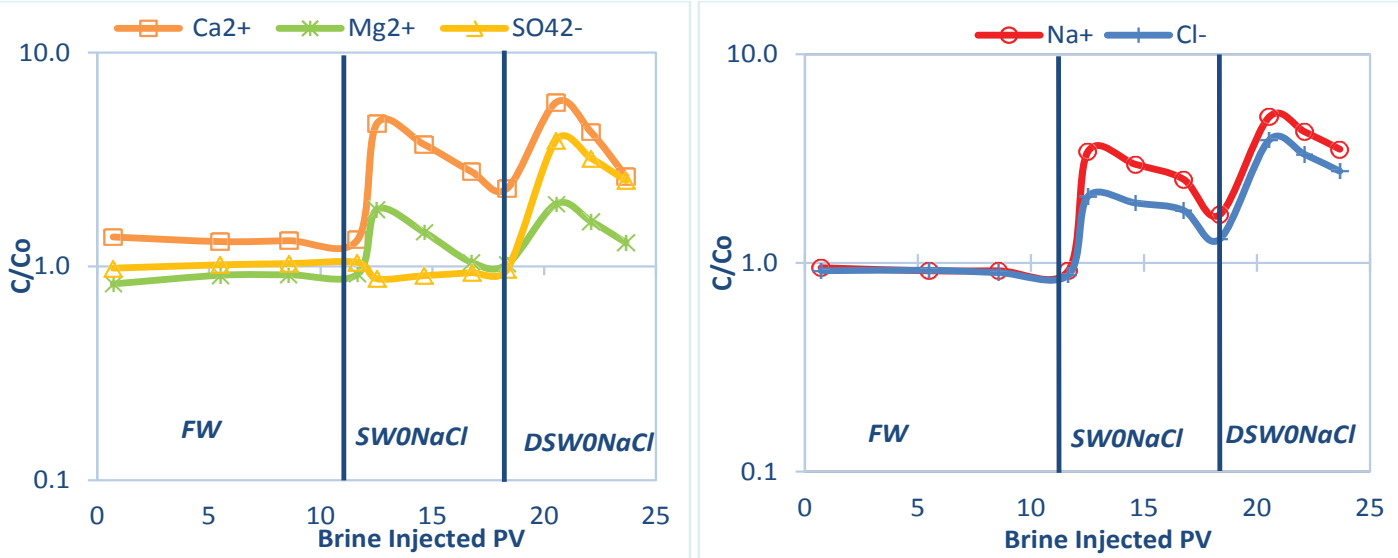

Figure 9: Breakthrough curves for Core flood 3.

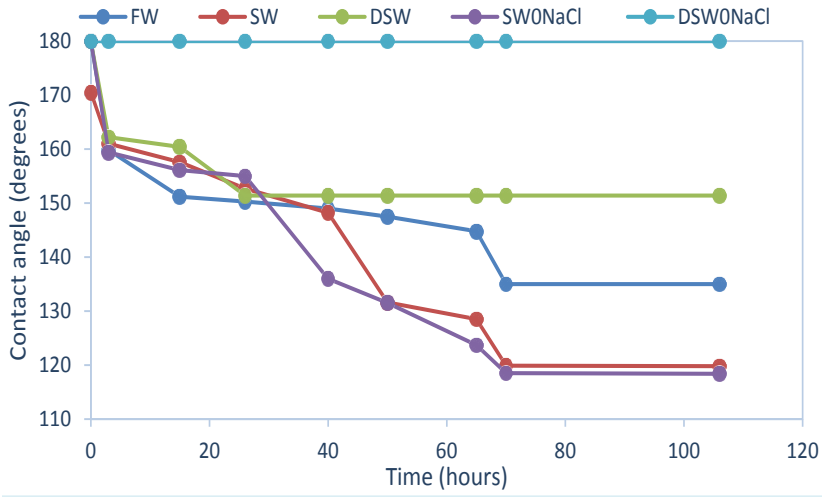

Figure 10: Contact angle as a function of exposure time.

from preferentially oil-wet state to weakly oil-wet state. Then with DSW, the contact angle measured with time was found within the preferentially oil-wet state which indicates that DSW was unable to alter wettability of the rock plate. Besides, $\mathrm{SW} 0 \mathrm{NaCl}$ gave a more water-wet nature with time as compared to DSW0NaCl which couldn't alter the rock wettability.

It is quite interesting to note that during the experiment core flood 2, DSW invading after SW couldn't increase the recovery since SW gave a more water-wetness compared to DSW. The ratio of ions in the diluted brines (DSW) was found to be same in SW while the ionic strength decreased by the dilution factor. Under this condition it was impossible to improve oil recovery by DSW due to the fact that there is reduced concentration of active ions as the brine was diluted. This same findings was reported by Fathi when no incremental recovery was observed when chalk core was flooded with diluted seawater because it gave low water-wet fraction compared to the original seawater [22].

But this findings seems to conflict with results from Yousef and Yi and Sarma $[15,16]$, they confirmed wettability alteration with dilution of invading brine salinity. They regarded this result to be due to rock microscopic dissolution, also in our case, rock dissolution seems to occur with the rock plates but the oil droplets vanished which made it hard to quantify. The discrepancies between our study and the reported results could be ascribed mainly to the particularity in rock characteristics, initial fluids composition, experimental conditions and procedures [30].
Observation here shows that FW couldn't change the wettability beyond the strongly oil-wet zone and SW decreased the wettability from strongly oil-wet to weakly oil-wet. Then considering seawater with its non-active ions depleted $(\mathrm{SWONaCl})$, contact angle decreased from $180^{\circ}$ to $118.4^{\circ}$, which indicates that the rock plate becomes relatively more water-wet as compared to SW. This shows that removal of $\mathrm{NaCl}$ salt from the invading brine could actually improve the waterwetness of the rock and improve oil recovery. This can be observed in coreflood 1 and coreflood 3 where injection of SWONaCl explicitly increased recovery beyond SW and FW respectively.

\section{Conclusions}

Finally, the multi-ion interaction leading to improved recovery by smart waterflooding was thoroughly investigated through series of experiment on candidate carbonate reservoirs. Based on the experimental findings, the following conclusions are drawn:

a) Direct relationships exist between $\mathrm{NaCl}$ depletion and zeta potential. For surface charge alteration to take place, there must a reduction in the ratio of $\mathrm{SO}_{4}^{2-}$ to $\mathrm{NaCl}$ in the injected smart brine.

b) Ultimate oil displacement increased relative to formation brine when $\mathrm{NaCl}$ was selectively removed from smart brine as compared to brine dilution.

c) Effluent concentration analysis presents evidence to support the multi-ion interaction occurring to influence wettability alteration through non-equilibrium state caused by surface charge and mineral alteration.

d) For effective Brine salinity reduction, a certain ion-ratio between the active and non-active ions should be maintained.

e) The degree of wettability alteration seems to be a function of the magnitude of surface charge alteration at the two interfaces: removal of $\mathrm{NaCl}$ gave a better alteration compared to brine dilution.

\section{Acknowledgment}

The authors appreciate the financial support provided by The Petroleum Institute (PI) in conducting this research work and the permission to present this paper. We thank ZADCO UZFDS Laboratory for helping with effluent sample analysis.

\section{References}

1. Jadhunandan PP (1990) Effects of brine composition, crude oil, and aging conditions on wettability and oil recovery. Department of Petroleum Engineering New Mexico Institute of Mining \& Technology, Mexico. 
Citation: Awolayo AN, Sharma HK (2016) Impact of Multi-ion Interactions on Oil Mobilization by Smart Waterflooding in Carbonate Reservoirs. J Pet Environ Biotechnol 7: 278. doi:10.4172/2157-7463.1000278

2. Tang GQ, Morrow NR (1997) Salinity, temperature, oil composition, and oil recovery by waterflooding. SPE Reservoir Engineering 12: 269-276.

3. Zhou X, Morrow NR, Ma S (2000) Inter-relationship of wettability, initial water saturation, aging time, and oil recovery by spontaneous imbibition and water flooding. SPE Journal 5: 199-207.

4. Zhang $P$, Austad $T$ (2006) Wettability and oil recovery from carbonates: Effects of temperature and potential determining ions. Colloids and Surfaces $A$ : Physicochemical and Engineering Aspects 279: 179-187.

5. Strand S, Austad T, Puntervold T, Høgnesen EJ, Olsen M, et al. (2008a) "Smart water" for oil recovery from fractured limestone: A preliminary study. Energy \& Fuels 22: 3126-3133.

6. Jadhunandan PP, Morrow NR (1995) Effect of wettability on water flood recovery for crude-oil/brine/rock systems. SPE Reservoir Engineering 10: 40-46.

7. Lager A, Webb KJ, Black C, Singleton M, Sorbie K (2008) Low salinity oil recovery-an Experimental investigation. Petrophysics. 49:1

8. Agbalaka CC, Dandekar AY, Patil SL, Khataniar S, Hemsath JR (2009) Core flooding studies to evaluate the impact of salinity and wettability on oil recovery efficiency. Transport in Porous Media 76: 77-94.

9. Austad T, Strand S, Høgnesen E, Zhang P (2005) Seawater as IOR fluid in fractured chalk. SPE-93000-MS. Proceedings of the SPE International Symposium on Oilfield Chemistry, The Woodlands, Texas.

10. Høgnesen E, Strand S, Austad T (2005) Water flooding of preferential oilwet carbonates: Oil recovery related to reservoir temperature and brine composition. SPE-94166-MS. Proceedings of the SPE Europe/EAGE Annual Conference, Madrid, Spain.

11. Zhang P, Tweheyo MT, Austad T (2006) Wettability alteration and improved oil recovery in chalk: The effect of calcium in the presence of sulfate. Energy \& Fuels 20: 2056-2062.

12. Zhang P, Tweheyo MT, Austad T (2007) Wettability alteration and improved oil recovery by spontaneous imbibition of seawater into chalk: Impact of the potential determining ions $\mathrm{Ca}^{2+}, \mathrm{Mg}^{2+}$, and $\mathrm{SO}^{2-}$. Colloids and Surfaces $\mathrm{A}$ : Physicochemical and Engineering Aspects 301: 199-208

13. Strand S, Puntervold T, Austad T (2008b) Effect of temperature on enhanced oil recovery from mixed-wet chalk cores by spontaneous imbibition and forced displacement using seawater. Energy \& Fuels 22: 3222-3225.

14. Austad T (2013) Understanding of the EOR Potential Using "Smart water" enhanced oil recovery field. Case Studies pp. 301.

15. Yousef A, Al-Saleh S, Al-Kaabi A, Al-Jawfi M (2010) Laboratory investigation of novel oil recovery method for carbonate reservoirs. SPE 137634-MS. Proceedings of the Canadian Unconventional Resources and International Petroleum Conference, Calgary, Alberta, Canada.

16. Yi Z, Sarma H (2012) Improving water flood recovery efficiency in carbonate reservoirs through salinity variations and ionic exchanges: A promising lowcost" smart-water flood" approach. SPE 161631-MS. Proceedings of the Abu Dhabi International Petroleum Conference and Exhibition, Abu Dhabi, UAE.
17. Chandrasekhar S, Mohanty K (2013) Wettability alteration with brine composition in high temperature carbonate reservoirs. SPE 166280. Proceedings of the SPE Annual Technical Conference and Exhibition, New Orleans, Louisiana, USA.

18. Yousef A, Liu J, Blanchard G, Al-Saleh S, Al-Zahrani T, et al. (2012) Smart water flooding: Industry's first field test in carbonate reservoirs. SPE-159526. Proceedings of the SPE Annual Technical Conference and Exhibition, San Antonio, Texas, USA.

19. Awolayo AN, Sarma HK, AISumaiti AM (2016) An experimental investigation into the impact of sulfate ions in smart water to improve oil recovery in carbonate reservoirs. Transport in porous media 111: 649-668.

20. Awolayo AN, Sarma HK, Al-sumaiti AM (2014) A laboratory study of ionic effect of smart water for enhancing oil recovery in carbonate reservoirs. SPE 169662. Proceedings of the SPE EOR Conference at Oil and Gas West Asia, Muscat, Oman.

21. Gupta R, Smith Jr P, Willingham T, Lo Cascia M, Shyeh J, et al. (2011) Enhanced water flood for middle east carbonate cores-impact of injection water composition. SPE 142668. Proceedings of the SPE Middle East Oil and Gas Show and Conference, Manama, Bahrain

22. Fathi SJ, Austad T, Strand S (2010) "Smart water" as a wettability modifier in chalk: The effect of salinity and ionic composition. Energy \& Fuels 24: 2514-2519.

23. Strand S, Høgnesen EJ, Austad T (2006) Wettability alteration of carbonates Effects of potential determining ions $\left(\mathrm{Ca}^{2+}\right.$ and $\left.\mathrm{SO}_{4}{ }^{2-}\right)$ and temperature. Colloids and Surfaces A: Physicochemical and Engineering Aspects 275: 1-10.

24. Gupta R, Mohanty K (2008) Wettability alteration of fractured carbonate reservoirs. SPE 113407-MS. Proceedings of the SPE/DOE Symposium on Improved Oil Recovery, Tulsa, Oklahoma, USA.

25. Nasralla RA, Alotaibi MB, Nasr-El-Din HA (2011) Efficiency of oil recovery by low salinity water flooding in sandstone reservoirs. SPE 144602. Proceedings of the SPE Western North American Regional Meeting, Anchorage, Alaska, USA

26. RezaeiDoust A, Puntervold T, Strand S, Austad T (2009) Smart water as wettability modifier in carbonate and sandstone: A discussion of similarities/ differences in the chemical mechanisms. Energy \& Fuels 23: 4479-4485.

27. Austad T, Shariatpanahi S, Strand S, Black C, Webb K (2011) Conditions fo a low-salinity enhanced oil recovery (EOR) Effects in carbonate oil reservoirs. Energy \& Fuels 26: 569-575.

28. Alotaibi MB, Azmy R, Nasr-El-Din HA (2010) Wettability challenges in carbonate reservoirs. SPE-129972-MS. Proceedings of the SPE Improved Oil Recovery Symposium, Tulsa, Oklahoma, USA.

29. Zahid A, Shapiro A, Skauge A (2012) Experimental studies of low salinity water flooding in carbonate reservoirs: A new promising approach. Paper SPE155625 l presented at the SPE EOR Conference at Oil and Gas West Asia, Muscat, Oman.

30. Tang GQ, Morrow NR (1999) Influence of brine composition and fines migration on crude oil/brine/rock interactions and oil recovery. Journal of Petroleum Science and Engineering 24: 99-111. 